\title{
Characteristics of Oder river water temperature for heat pump
}

\author{
Marderos Ara Sayegh ${ }^{1, *}$, and Alina Żabnieńska-Góra ${ }^{1}$ \\ ${ }^{1}$ Wroclaw University of Science and Technology, Faculty of Environmental Engineering, \\ Wybrzeze Wyspianskiego 27, 50-370 Wroclaw, Poland
}

\begin{abstract}
Currently there is increasing interest in using surface water bodies as renewable energy sources for year around or seasonal heating and cooling applications e.g. heat pumps. This paper presents the statistical analysis of average water temperature and the flow rate of the Oder River. Linear regression analysis was carried out on the base of ten years (2005-2014) diurnal water temperatures measurements data. The results determine the relation between average air temperature in Wroclaw and Oder river water average temperature for two analysed locations. The Pearson's $\mathrm{r}$ correlation coefficients were determined. Additionally, the variability of water flow rates from 2008-2010 in the annual cycle were illustrated. The article proposes the conceptual framework for surface water bodies technical aspects. This proposition is the first step for wider analysis in order to identify the thermal potential of the Oder river water as heat source for heat pumps.
\end{abstract}

\section{Introduction}

The rapidly growing human population and rising need for renewable energy increase the demand for thermal use of waterbodies for heating and cooling applications [1]. The analysis demonstrates that waterbodies provide real alternatives for heat/cold production in many regions of the world. Many of our towns and cities are located close to large water sources, so considerable heat is available in our surface water bodies like rivers, ponds, lakes, canals and in the seas that surround us [1,2].

When using the thermal energy of these water bodies, it is important not to alter significantly their thermal regime, but simultaneously to avoid waterbodies environmental disturbance or their ecosystem disruption too. Matching surface water resources like river water with the national or local renewable energy source heat map means that we can enable the potential of these heat sources against heat demand densities. This will guide the heat networks, e.g. making use of water source heat pumps, are more likely to be viable [3]. River water is a huge thermal reservoir of un-tapped potential. Improving the understanding of the temperature regime and the thermal processes will help to determine general thermal characteristics of river water temperature variability and water flow. They are essential and have been promoted recently by the debate on climate change [3].

\footnotetext{
*Corresponding author: ara.sayegh@pwr.edu.pl
} 
This work is one of the first researches to ask about the thermal potential of Oder river and further its feasibility scale for using this river water as a year around or seasonal heat source e.g. for heat pumps [3-5].

The main aim of this paper is to identify the temperatures characteristic of lower Silesian Oder river water courses, especially in Wroclaw and periphery areas where environmental factors (atmospheric conditions, air temperature etc.) influencing on the thermal regime of river water may potentially constrain water source heat pump applications for suitable heat demand of district heating network, domestic hot water applications for individual dwellings, single buildings etc. River water temperature models are generally classified into three groups: regression, stochastic and deterministic models [6].

In this article statistical analysis (linear regression) was provided to determine the relation between the diurnal river water average temperature and diurnal air average temperature on the basis of archival measurement data conducted by the Institute of Meteorology and Water Management of the National Research Institute (IMGW-PIB) in the period from 2005 to 2014 [7]. The Pearson's $r$ correlation coefficient between variables were determined. Additionally, the variability of water flow rates from 2008-2010 in the annual cycle were illustrated. The analysis was carried out for two locations of the Oder river, situated about $133 \mathrm{~km}$ apart and flowing through Lower Silesia, in the context of the possibility of using Oder river thermal potential for heating and cooling purposes.

\section{Conceptual framework and technical aspects for river water potential}

The complexity of river thermal response depends on the temporal and spatial scales, short-term estimates being more challenging since they are affected by a multiplicity of local factors (e.g. cloudiness, vegetation shadowing, topographic heterogeneity, anthropogenic), or even sometimes intermittently water drops to the river basin from the industrial processes and with less quality water treatment processes. So the external natural and local municipal factors influencing on the thermal characteristics of the river water becoming more difficult to assessment.

The impacts of using waterbodies for heating, cooling applications have also been scarcely studied. There is a growing body of river water thermal research but there is still limited understanding of large-scale spatial and temporal variability of the thermal characteristics, and their influence on river basin properties $[1,8]$.

Rivers compared to lakes and other water reservoirs, tend to be less stratified and more closely follow air temperatures. River temperatures are affected by atmospheric conditions, shading, the nature of the flow, groundwater inflows and anthropogenic factors (mainly discharges of waste water etc.) [9].

Careful planning of thermal use infrastructure is decisive for the economic and technical viability of heating cooling system e.g. heat pumps. Even though the technical knowledge of heating and cooling is well established, but thermal use of waterbodies is still limited [10]. However, with increasing pressure towards reduction of $\mathrm{CO}_{2}$ emissions, there is growing interest in the vast potential offered by surface waterbodies for heating and cooling throughout the world [3, 8-10].

Operacz [11] proposed a term of "effective potential" to allow the energy production estimation from Raba river in Poland with the method closest to the real possibilities of execution of new hydropower plants. 
The authors in this paper propose the conceptual framework as an approach for technical and thermal aspects for river water potential which is illustrated in Figure 1 and described as follow.

1 Surface waterbodies ecosystem potential: Thermal characteristics of riverine ecosystems are dependent on theirs hydrological, meteorological, climatological, terrain morphology, biological and anthropogenic environment. The relative importance of these features differs amongst rivers $[2,5,12]$.

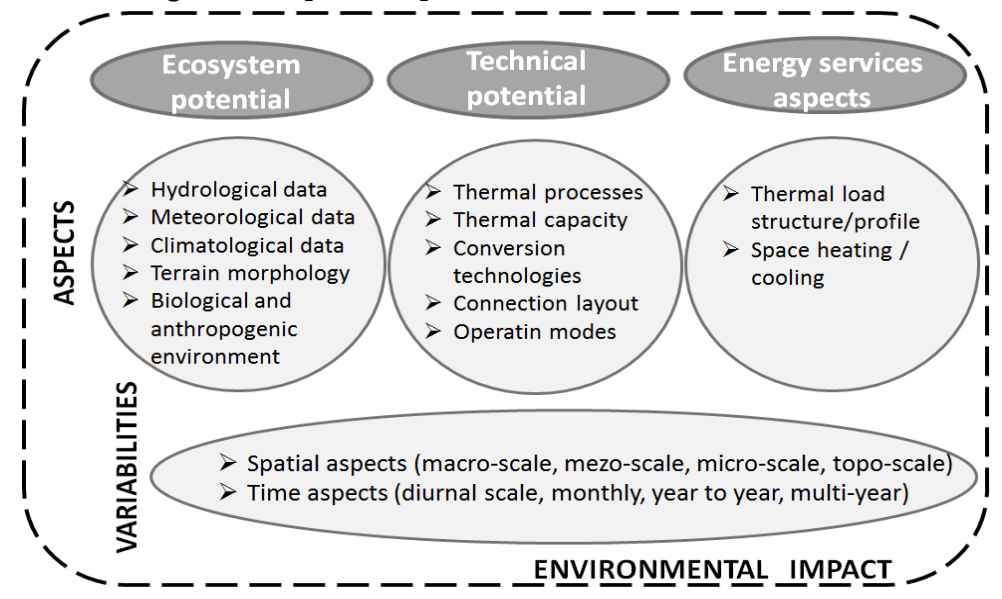

Fig. 1. Conceptual framework of surface water bodies technical aspects.

2 Surface waterbodies technical potential: The technical potential takes into account possibility of pursue a specific objective through an increase in deployment of existing technologies or implementation of such processes and practices of energy systems that couldn't have been used before due to technical limitations such as conversion efficiencies etc. The technical potential includes geographical restrictions as well as technical and structural constraints. The technical potential would increase if it can be exploit economically at a competitive costs, taking into account other considerations, like social or environmental considerations [9, 10].

3 Surface waterbodies energy services potential: Waterbodies services potential generally mean modes of heat/cold extraction from water bodies and use it in applications for thermal use like heating and cooling demand (e.g.: domestic hot water, swimming pools or industrial processes). Heat exchange concerns with applications efficiencies like heat pumps coefficient COP, water volume needed, fraction of river flow etc. This potential follows a strong seasonal pattern [1,9-11].

\section{Characteristics of the Oder river and study area}

After the Vistula, the Oder is the second longest river in Poland and one of the largest rivers in the Baltic Sea catchment area. It covers south-western, western and north-western Poland. Table 1 describes some of the characteristics of the main rivers in Poland. It is a river with great opportunities for its economic development including the construction and development of hydrotechnical infrastructure. From the very beginning it was used for transport and energy purposes, previously also for water supply.

The analysed area is located in the river basin of the middle Oder and is a part of the Wroclaw proglacial stream valley as in Figure 2. It covers a section of the Oder River with a length of about $133 \mathrm{~km}$. The first measuring station of diurnal river water temperature 
is located in the place where the Oder river flows into the Brzeg (location A - $50 \mathrm{~km}$ below Wroclaw), the second measuring station in the place where the Oder river flows out of the Scinawa (location B $-80 \mathrm{~km}$ above Wroclaw). Throughout the entire section of the canalized Oder, a depth of $1.8 \mathrm{~m}$ is ensured throughout the entire sailing season, lasting on average 270 days. The delimited area presented in Figure 2 therefore can be suitable area for analysing the possibility of using Oder river as a heat source for cooling and heating applications. Oder River below the last barrage in Brzeg Dolny (30 km above Wroclaw), is a free-flowing river, that exerts a draining effect on adjoining areas. After damming, the adjoining areas above the barrage in Malczyce (55 km above Wroclaw) will fall within the infiltrating influence of the river, hence some areas may become overly moist or vulnerable to flooding [13].

Table 1. Some of the characteristics of the main rivers in Poland.

\begin{tabular}{|c|c|c|c|c|}
\hline River & $\begin{array}{c}\text { River length } \\
{[\mathbf{k m}]}\end{array}$ & $\begin{array}{c}\text { River length } \\
\text { in Poland }[\mathbf{k m}]\end{array}$ & $\begin{array}{c}\text { River basin area } \\
\text { (in Poland) }\left[\mathbf{k m}^{\mathbf{2}}\right]\end{array}$ & $\begin{array}{c}\text { Average annual } \\
\text { flow at the estuary } \\
{\left[\mathbf{m}^{\mathbf{3}} / \mathbf{s}\right]}\end{array}$ \\
\hline Vistula & 1048 & 1048 & 194424 & 1080 \\
\hline Oder & 854 & 742 & $118861(106056)$ & 567 \\
\hline
\end{tabular}

The diurnal average air temperature is the key variable for the diurnal average water temperature. The measuring station is located in Wroclaw, in the center of the analysed area. Wroclaw is one of the warmest cities in Poland. The annual mean temperature for Wroclaw is $8.7^{\circ} \mathrm{C}$ and relative humidity about $75 \%$. Total annual precipitation recorded for the city (in Wroclaw-Strachowice station) over the years 2000-2014 is $574.4 \mathrm{~mm}$. The warmest month is July, which is also the time of the biggest sum of monthly rainfall. January is the coldest month and February is the month with lowest monthly rainfall [13].

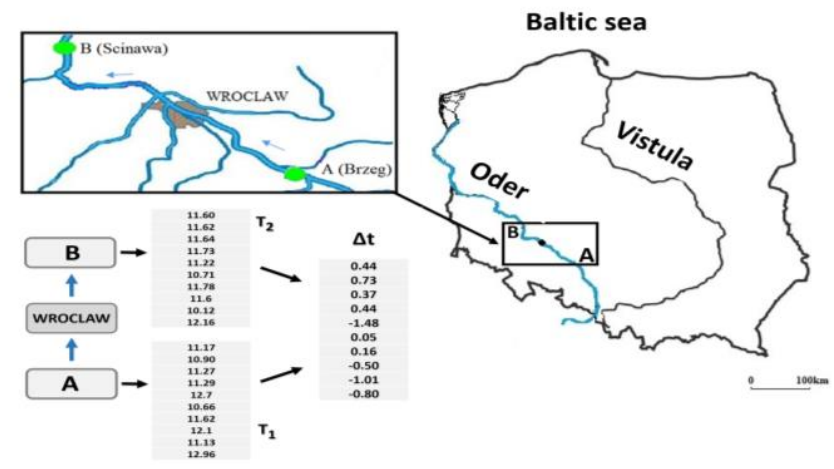

Fig. 2. Characteristics of the study area.

In this article results of ten years measurements of diurnal water temperatures and water flow rates archival data from the database of Institute of Meteorology and Water Management of the National Research Institute (IMGW-PIB) were analysed for two measurement locations: A (Brzeg) and B (Scinawa) and illustrated in Figure 2, where T1, T2 are the Oder river water average temperatures in locations A, B respectively in period 2005-2014. The analysis also includes measurement data of the average diurnal air temperature in the years 2005-2014 from the meteorological measurement station Wroclaw-Strachowice. Water temperature measurements take place in the hydrological measuring and observation stations at a depth of $0.4 \mathrm{~m}$ in accordance with the recommendations of the World Meteorological Organisation (WMO) [7], which ensure the 
reliability of the measurements data. The measurement locations A and B have been selected above because in this section the Oder River is canalized. This selection guarantees and conserve the required water level and water flow rate. Additionally the hydrology of the upper and partly central Oder River outside the precipitation and evaporation is determined by the reservoir retention. In the remaining section of the freely flowing river, the Oder river has a variable water flow rate over time, and the water level depend on both of water content for the given year, as well as on a specific part of the navigation season [14]. Several rivers connect with the Oder within Wroclaw (the main rivers are: Bystrzyca, Olawa, Sleza, Widawa). Therefore, according to the authors, the delimited locations will be profitable to plan new districts not far from the Oder river, in Wroclaw and/or in locations $\mathrm{A}$ and $\mathrm{B}$, so there will be possible for implementing heating or cooling applications in new districts, so to use the Oder river water as a heat source for heat pumps.

\section{Statistical analysis of water temperatures and flow rates}

In order to use the river water as heat source for heating and cooling applications like heat pump, the thermal potential of the river should be estimated. The first step is to determine the temperature range of the river on a year-round cycle and its dependence on atmospheric conditions. The most important atmospheric variable is the air temperature. A literature review has shown that there are many methods to determine the relationship between the river water temperature and air temperature. Water temperature models are generally classified into three groups: regression, stochastic and deterministic models. Deterministic models employ an energy budget approach to predict river water temperature, whereas regression and stochastic models generally rely on air to water temperature relationships. Linear regression models are commonly, allow to estimate the river average water temperature under conditions caused by climate changes, and to determine the range of underground supply, as well as its impact on the thermal conditions of the river. As a first step this paper will deal with the linear model. The strength of the relationship between water temperature and air temperature is reflected in the values of the correlation coefficient. The application of the correlation (linear regression) method to investigate the relationships of long-term measurement series between two variables requires a large data and allows for presenting reliable results [15].

\subsection{River water temperatures}

In the measured period (2005-2014), the diurnal average water temperature of Oder river and air average temperature did not drop below $1.4^{\circ} \mathrm{C}$ and $-4.4^{\circ} \mathrm{C}$, respectively. For mentioned measurement period the share of average air temperature below $0^{\circ} \mathrm{C}$ is only $11.75 \%$ per year and temperatures above $20^{\circ} \mathrm{C}$ are $7.56 \%$.

The majority of measurements share is in the range from $0^{\circ} \mathrm{C}$ to $20^{\circ} \mathrm{C}$ are over $80 \%$. It is worth to noting that the drop in average water temperature below $5^{\circ} \mathrm{C}$ around the year is $27.87 \%$ and $30.06 \%$ at the location A and B respectively. This is due to the high level of urbanization of the area below point A.

The majority of measurements are in the range from $5^{\circ} \mathrm{C}$ to $20^{\circ} \mathrm{C}$, which is over $51.91 \%$ and $48.09 \%$ for the locations $\mathrm{A}$ and $\mathrm{B}$ respectively. The percentage of river water average temperature above $20^{\circ} \mathrm{C}$ is $16.94 \%$ and $21.58 \%$ for the locations $\mathrm{A}$ and $\mathrm{B}$ respectively and is higher than in case of air temperature which is $7.64 \%$. This is related to the ability to heat accumulation in the river water. Figure 3 illustrates the variability of average Oder water temperature and average Wroclaw air temperature during the period 2005-2014. 


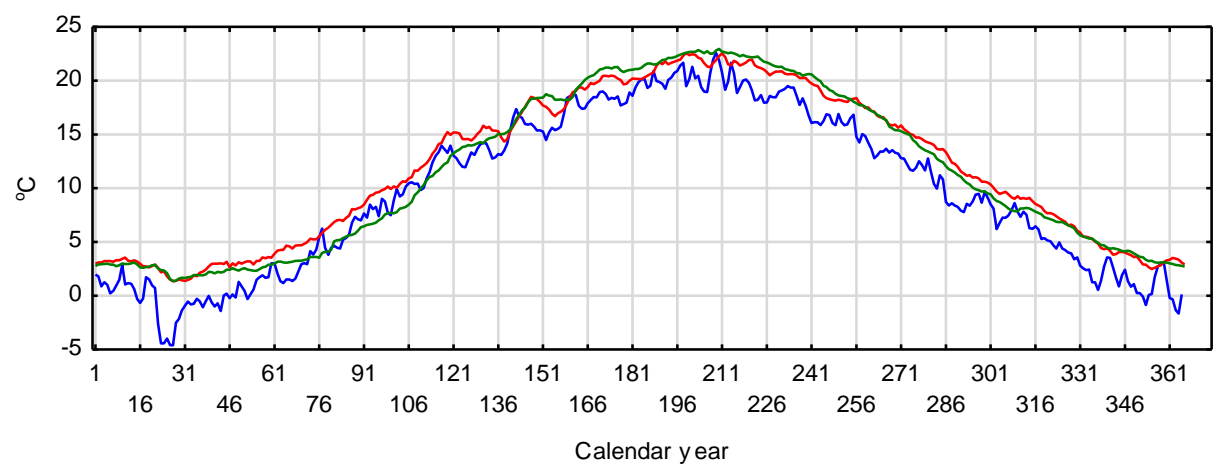

- Average air temperatures - Wrocław

- Av erage riv er water temperatures - Brzeg

- Average river water temperatures - Ścinawa

Fig. 3. Average water and air temperatures within the measured period 2005-2014.

The relation between average water temperature (in locations A and $\mathrm{B}$ ) and average air temperature by means of a linear function described by the formula:

$$
T_{r w}=a T_{a}+b
$$

where: $T_{r w}-$ is river water temperature, $T_{a}-$ is air temperature, $a$ and $b$-constants.

Figure 4 shows a scatter chart for average air temperature in Wroclaw and Oder river water average temperature at individual measuring locations of $\mathrm{A}$ and $\mathrm{B}$.
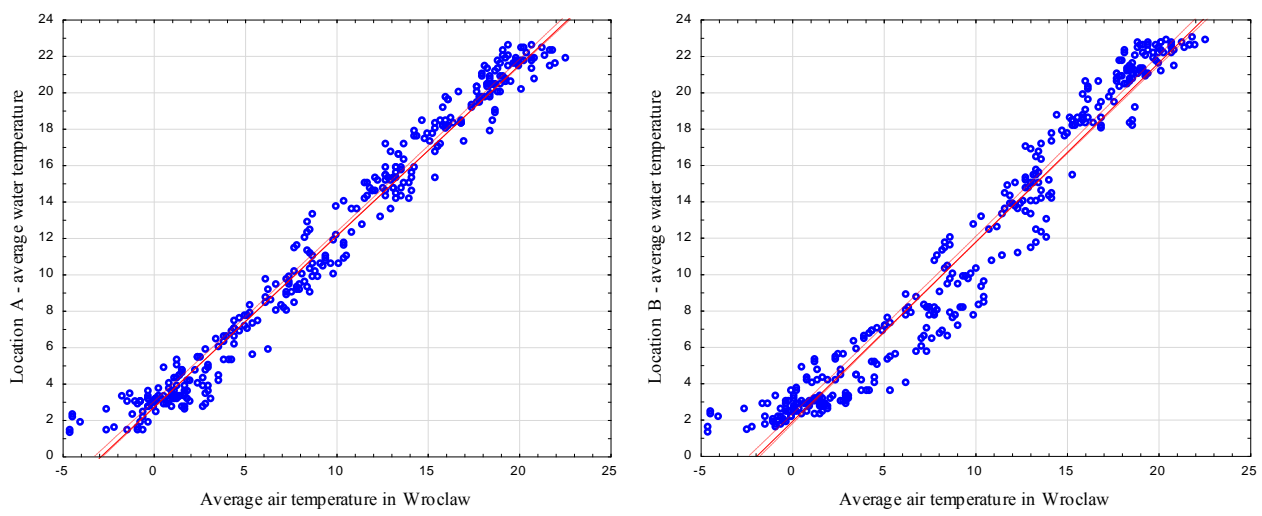

Fig. 4. Scatter chart for average air temperature in Wroclaw and Oder river water average temperature at measuring locations $\mathrm{A}$ and $\mathrm{B}$.

In addition, Pearson's $r$ correlation coefficients between air temperature and water temperature at each measuring location were determined as follow:

$$
r_{A B}=\Sigma\left(Y_{\text {iA }}-Y_{\text {averageA }}\right) \cdot\left(Y_{i B}-Y_{\text {averageB }}\right) /\left[\Sigma\left(Y_{\text {iA }}-Y_{\text {average } A}\right)^{2} \cdot \Sigma\left(Y_{i B}-Y_{\text {averageB }}\right)^{2}\right]^{(1 / 2)}
$$

The results of the analyses of the annual average temperature of Oder river water were compared with the average annual air temperature in Wroclaw. The Pearson's correlation 
coefficient for the analyzed data was for location A $r=0.9887$ and for location B is $\mathrm{r}=0.9774$. Confidence interval is $95 \%$. Thus the average water temperature can be formulated by means of a linear regression at locations $\mathrm{A}$ and $\mathrm{B}$ as follow:

$$
\begin{aligned}
T_{A} & =0.9887 \cdot \mathrm{Ta}+2.757 \\
T_{B} & =0.9774 \cdot \mathrm{Ta}+1.9415
\end{aligned}
$$

The results of analysis show the variability of thermal characteristics of Oder river at the entrance and exit locations for the analysed delimited area. As a correlation result the average air temperature in Wroclaw for location A better describes the Oder river average water temperature.

\subsection{River water flow rates}

The middle and lower Oder river in 1961-1990 demonstrated a noticeable increase of river water flow in the winter season (from December to early February) and also in late spring and early summer (from May to July) [16]. This study showed distinct decline in winter flow and a delayed rise in spring meltwater flow the recorded in 1950s and 1960s. On the other hand, in the 1970s and 1980s there were no winter base flows recorded, normally resulting from a significant increase of winter flows, which sometimes prolong relatively lower increases of spring flows. Thus, the effect of North Atlantic Oscillation (NAO) on the hydrological cycle in Poland was found [16].

Figure 5 illustrates the variability of the average annual water flow rate in the analysed area (for locations A and B). Analysis of the flow rates in the years 2008-2010 confirms the increase in spring water flow rate resulting from winter melts and increased rainfall in the early summer. The average flow rate at the analysed points in the years 2008-2010 was: $196.18 \mathrm{~m}^{3} / \mathrm{s}$ for location A and $215.98 \mathrm{~m}^{3} / \mathrm{s}$ for location $\mathrm{B}$. The minimum flow rate for location A was $101.67 \mathrm{~m}^{3} / \mathrm{s}$ and for location $B$ was $112.73 \mathrm{~m}^{3} / \mathrm{s}$ and the maximum flow rate was $805.33 \mathrm{~m}^{3} / \mathrm{s}$ and $814.33 \mathrm{~m}^{3} / \mathrm{s}$ for locations $\mathrm{A}$ and $\mathrm{B}$ respectively.

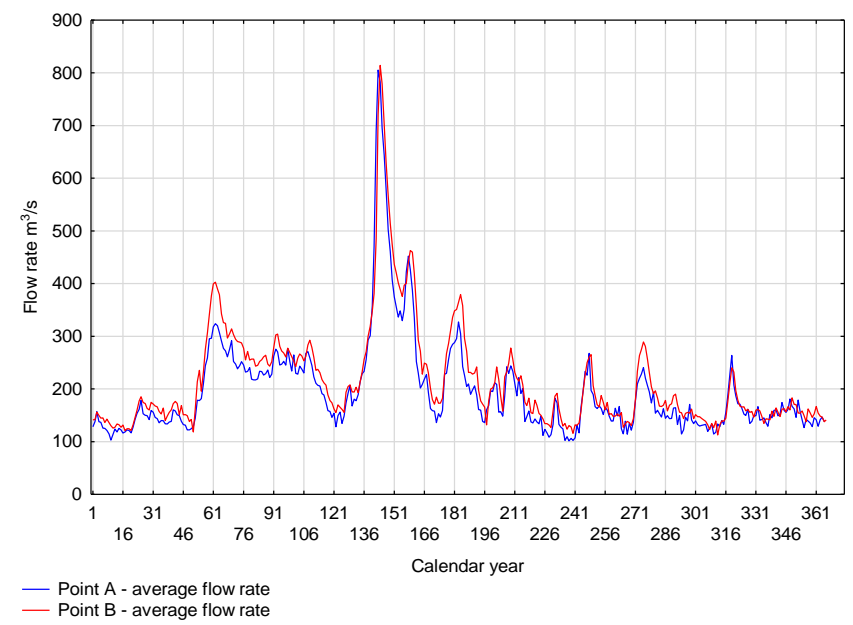

Fig. 5. The average annual water flow rate in locations A and B during 2008-2010.

Most of the data carried out belong to the flow range: $100-300 \mathrm{~m} / \mathrm{s}$, for point $\mathrm{A}$ it is $91.5 \%$ and for point $\mathrm{B}$ it is $87.1 \%$. Despite the distance between the measuring locations of $133 \mathrm{~km}$, the difference in flow rates is approx. $2-10 \%$. The analysis confirmed a noticeable 
increase in flow rate after the winter season (in March) and also in late spring (from May to July). Authors recommend further analyses of precipitation intensity and influence of ice phenomena on the Oder River as well as the water level and their influence on Oder thermal characteristics.

\section{Conclusions}

The article presents a statistical approach to the relationship between average air temperature in Wroclaw and average water temperature of Oder river for two analysed locations. Linear regression analysis was provided on the basis of ten year measurements archival data from 2005-2014, thereby ensuring the reliability of the analyses. The Pearson's $\mathrm{r}$ correlation coefficient was determined for two analysed location: for A is $r=0.9887$ and for $B$ is $r=0.9774$. It was found that the average water temperature can be formulated by means of a linear regression (equations 3 and 4 for locations $\mathrm{A}$ and $\mathrm{B}$ ). In the analysed area the above statistical relationships can be used to describe the river water temperature as a basic indicator for thermal regime in the Oder river. Additionally, the variability of water flow rates from 2008 to 2010 in the annual cycle was investigated and illustrated. The authors in this paper propose the conceptual framework for technical and ecosystem aspects to identify the river thermal characteristics as it's potential for using surface water bodies as renewable heat sources for heat pumps.

\section{References}

1. A. Gaudard, C. Weber, T. J. Alexander, S. Hunziker, M. Schmid, WIREs Water, 5 (2018)

2. A. Beaufort, F. Moatar, F. Curie, A. Ducharne, V. Bustillo, D. Thiéry, River Res. \& Applications, 32 (2016)

3. Technology Roadmap Energy-efficient Buildings: Heating and Cooling Equipment, International Energy Agency (IEA) (2011)

4. M.-A. Millar, N. M. Burnside, Y. Zhibin, Energies, 12 (2019)

5. B. W Webb, D. M. Hannah, R. D. Moore, L. E. Brown., F. Nobilis, Hydrological Processes 22, 7 (2008)

6. D. Caissie, Freshwater Biology, 51 (2006)

7. www.imgw.pl

8. C. L. R Laizé, C. B. Meredith, M. J .Dunbar, D. M. Hannah, Hydrology \& Earth System Sciences, 21 (2017)

9. J. D Spitler, K. Bashyam, G. Hansen, M. Mitchell, M. Selvakumar, Draft Final Report (ASHRAE 1385-RP, 2014)

10. A. Gaudard, A. Wüest, M. Schmid, Renewable Energy, 134 (2019)

11. A. Operacz, Renewable and Sustainable Energy Reviews, 75 (2017)

12. H. Dallas, Water SA 34, 3 (2008)

13. M. Chalfen, W. Lyczko, L. Plywaczyk, J. Water Land Dev. 21, 4-6 (2014)

14. Maritime Academy in Szczecin Institute of Transport Engineering Inland Navigation and Water Management Department (2006)

15. L. Wiejaczka, Scientific Review - Engineering and Environmental Design, 53 (2011)

16. D. Wrzesinski, L. Sobkowiak, J. Hydrol. Hydromech. 66 (2018) 